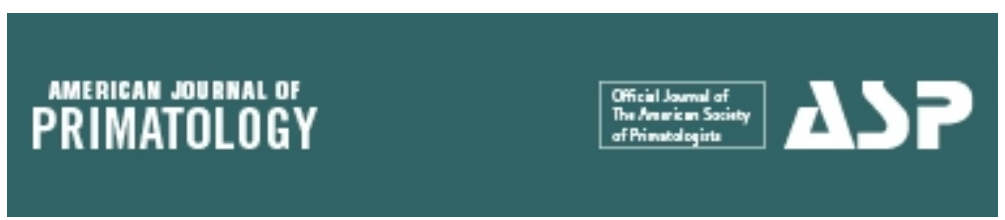

\title{
Phylogenetic relationships in the genus Cheracebus (Callicebinae, Pitheciidae)
}

\begin{tabular}{|c|c|}
\hline Journal: & American Journal of Primatology \\
\hline Manuscript ID & AJP-19-0267.R1 \\
\hline Wiley - Manuscript type: & Research Article \\
\hline $\begin{array}{r}\text { Date Submitted by the } \\
\text { Author: }\end{array}$ & 02-Feb-2020 \\
\hline Complete List of Authors: & $\begin{array}{l}\text { Carneiro, Jeferson; Universidade Federal do Pará, Genomics and } \\
\text { Systems Biology; Universidade Federal do Pará, Instituto de Estudos } \\
\text { Costeiros } \\
\text { Sampaio, Iracilda; Universidade Federal do Para, Instituto de Estudos } \\
\text { Costeiros; Universidade Federal do Pará, Genomics and Systems Biology } \\
\text { Lima, Thaynara; Universidade Federal do Para, Instituto de Estudos } \\
\text { Costeiros } \\
\text { Silva Júnior, Jose; Museu Paraense Emilio Goeldi, Zoologia } \\
\text { Farias, Izeni; Universidade Federal do Amazonoas, } \\
\text { Hrbek, Tomas; Universidade Federal do Amazonoas, Laboratory of } \\
\text { Evolution and Animal Genetics } \\
\text { Valsecchi, João; Instituto de Desenvolvimento Sustentável Mamirauá, } \\
\text { Grupo de Ecologia de Vertebrados Terrestres } \\
\text { Boubli, Jean; University of Salford, School of Environment and Life } \\
\text { Sciences } \\
\text { Schneider, Horacio; Universidade Federal do Para - Instututo de Estudos } \\
\text { Costeiros; Universidade Federal do Pará, Genomics and Systems Biology }\end{array}$ \\
\hline $\begin{array}{r}\text { Indicate which taxonomic } \\
\text { group was the subject of your } \\
\text { study (select all that apply or } \\
\text { type another option): }\end{array}$ & New World monkeys, Pitheciidae, Callicebinae, $<$ i $>$ Cheracebus $</$ i $>$ \\
\hline Keywords: & titi monkeys, New World monkeys, Phylogeny, Taxonomy \\
\hline
\end{tabular}

\section{SCHOLARONE ${ }^{m}$ Manuscripts}


1 Phylogenetic relationships in the genus Cheracebus (Callicebinae, Pitheciidae)

2 Jeferson Carneiro ${ }^{1,2}$, Iracilda Sampaio ${ }^{1,2}$, Thaynara Lima $^{2}$, José de Sousa and SilvaJúnior $^{3}$, Izeni Farias ${ }^{4}$, Tomas Hrbek ${ }^{4}$, João Valsecchi ${ }^{5}$, Jean Boubli ${ }^{6}$, Horacio

$6 \quad{ }^{1}$ Genômica e Biologia de Sistemas, Universidade Federal do Pará, Belém, Brazil

$7 \quad 2$ Instituto de Estudos Costeiros, Universidade Federal do Pará, Campus Universitário de

8 Bragança, Pará, Brazil

$9 \quad{ }^{3}$ Museu Paraense Emílio Goeldi, Mammalogy, Belém, Pará, Brazil

$10{ }^{4}$ Universidade Federal do Amazonas, Laboratory of Evolution and Animal Genetics,

11 Manaus, Amazonas, Brazil

$12{ }^{5}$ Mamirauá Sustainable Development Reserve, Amazonas, Brazil

$13{ }^{6}$ School of Environment and Life Sciences, University of Salford, Salford, UK

15 Running title: Phylogeny Cheracebus

16

17 Corresponding author: Jeferson Carneiro

18 E-mail: jeferson.carneiro@yahoo.com 


\section{Carneiro 2}

\section{Abstract}

20 Cheracebus is a new genus of New World primate of the family Pitheciidae, subfamily

21 Callicebinae. Until recently, Cheracebus was classified as the torquatus species group

22 of the genus Callicebus. The genus Cheracebus has six species: C. lucifer, C. lugens, $C$.

23 regulus, C. medemi, C. torquatus, and C. purinus, which are all endemic to the Amazon

24 biome. Prior to the present study, there had been no conclusive interpretation of the

25 phylogenetic relationships among most of the Cheracebus species. The present study

26 tests the monophyly of the genus and investigates the relationships among the different

27 Cheracebus species, based on DNA sequencing of 16 mitochondrial and nuclear

28 markers. The phylogenetic analyses were based on Maximum Likelihood, Bayesian

29 Inference and multi-species coalescent approaches. The divergence times and genetic

30 distances between the Cheracebus taxa were also estimated. The analyses confirmed the

31 monophyly of the genus and a well-supported topology, with the following

32 arrangement: ((C.torquatus, C. lugens), (C. lucifer, (C. purinus, C. regulus))). A well-

33 differentiated clade was also identified within part of the geographic range of C. lugens,

34 which warrants further investigation to confirm its taxonomic status.

35 Key words: titi monkeys, New World monkeys, phylogeny, taxonomy 
36

37

\section{Introduction}

The titi monkeys are small to medium sized (adult body weight $1-2 \mathrm{~kg}$ ) New

World primates of the family Pitheciidae. The monophyly of this group was not recognized until the beginning of the 20th Century, and the species had been allocated to a number of different genera, including Callithrix and Saguinus (see Hershkovitz, 1963). Thomas (1903) placed all the titis described up to that time in the genus Callicebus. Hershkovitz (1963) recognized two species, Callicebus moloch, with seven subspecies, and Callicebus torquatus, with three subspecies. Subsequently, following the analysis of a much larger sample of specimens and geographic localities, Hershkovitz $(1988,1990)$ updated the diversity of the genus to 13 species and a total of 25 taxa. These species were arranged in four species groups, based on their morphological similarities and geographic ranges (Table 1).

Kobayashi and Langguth (1999) accepted the species group approach of Hershkovitz (1988, 1990), but proposed an arrangement with five groups. This arrangement was followed by van Roosmalen et al. (2002), who also considered all the subspecies to be valid species. Groves (2005) subsequently proposed the division of Callicebus into two subgenera, one of which, Torquatus, included the species of the torquatus group, with all the other species being allocated to the subgenus Callicebus. This arrangement was followed by Silva-Júnior et al. (2013). Recently, Byrne et al. (2016) proposed the division of Callicebus into three genera, based primarily on divergence times, including two new genera, given the lack of available nomina. The two new genera were designated Plecturocebus (composed of the species of the donacophilus, cupreus and moloch species groups) and Cheracebus (composed of the species of the torquatus group). The species of the personatus group remained in the 
60 genus Callicebus. The classification proposed by Byrne et al. (2016) was adopted in

61 the present study.

A variety of taxonomic arrangements have been proposed for the titi monkeys since the middle of the 20th Century, although the same six taxa compiled the torquatus species group of Hershkovitz (1988, 1990), Groves' (2005) Torquatus subgenus, and the genus Cheracebus of Byrne et al. (2016). These taxa are denominated here as Cheracebus torquatus (Hoffmannsegg, 1807), Cheracebus purinus (Thomas, 1927), Cheracebus lucifer (Thomas, 1914), Cheracebus lugens (Humboldt, 1811), Cheracebus regulus (Thomas, 1927), and Cheracebus medemi

69 (Hershkovitz, 1963). The one exception has been the proposal of Kobayashi (1995),

70 based on a geometric morphometric analysis, which placed the C. purinus in the personatus species group, the current genus Callicebus.

Cheracebus is endemic to the Amazon region, and the species are assumed to have an allopatric distribution, with species ranges separated by major rivers (Figure 1). The exact limits between the ranges of some species are still unclear, however, due 75 primarily to the sampling deficiencies of many areas, as in the case of $C$. lucifer and $C$. medemi, which both occur between the Japurá/Solimões and Caquetá/Aguarico rivers,

77 and are not separated by any obvious physical barrier. There are also a number of 78 discrepancies on the distributions of C. torquatus and C. lugens. Hershkovitz (1990) 79 suggested that a sympatric zone exists between these two species, while van 80 Roosmalen et al. (2002) concluded that $C$. lugens occupies an extensive area to the 81 north of the Branco River, including the basins of the Branco and Orinoco rivers, and a 82 number of other, smaller rivers, whereas $C$. torquatus is restricted to the area between 
the Japurá and Negro rivers. However, Casado et al. (2006) proposed that C. lugens occurs on both margins of the Negro River, in agreement with Hershkovitz (1990).

a first phylogenetic arrangement of the species of the genus based on DNA sequencing of mitochondrial and nuclear markers.

\section{Material and Methods}

Samples, and the Extraction, Amplification, and Sequencing of the DNA

Samples of blood and muscle tissue were obtained from 26 pitheciid specimens,

including 17 representatives of five of the six Cheracebus species (1 C. torquatus, 6 C. lugens, 3 C. purinus, 3 C. lucifer, 4 C.regulus, 3 Plecturocebus, 3 Callicebus, 1

Chiropotes, 1 Cacajao, and 1 Pithecia). No samples of Cheracebus medemi could be obtained for analysis in the present study. The samples (Table 2, Figure 1) were identified based on the morphological traits of the specimens, which were compared the Federal University of Amazonas (UFAM) in Manaus, the Rio de Janeiro Primatology Center (CPRJ), the Pontifical Catholic University of Minas Gerais (PUC) according to the manufacturer's protocol, and 16 molecular markers were amplified by

104 Polymerase Chain Reaction, PCR (Table 3). These markers included three fragments of

105 the mitochondrial DNA - Cytochrome oxidase subunit I (COI), Cytochrome b (Cytb), 
107 Alu elements together with their flanking regions. The PCRs were standardized to a

108 final volume of $15 \mu 1$, containing $30 \mathrm{ng}$ of genomic DNA, $2.4 \mu 1$ of dNTPs $(1.25 \mathrm{mM})$;

$1091.5 \mu \mathrm{l}$ of $10 \mathrm{X}$ buffer $(200 \mathrm{mM}$ Tris- $\mathrm{HCl}, 500 \mathrm{mM} \mathrm{KCl}) ; 1 \mu 1$ of $\mathrm{MgCl}_{2}(25 \mathrm{mM}) ; 1 \mu 1$ of

110 each primer $(0.2 \mu \mathrm{M})$, and $1 \mathrm{U}$ of Taq DNA polymerase. With the exception of the

111 primer annealing temperatures, all other steps of the amplification protocol were

112 identical for all the markers. The thermocycler was programmed for the following

113 schedule: initial denaturation at $95^{\circ} \mathrm{C}$ for $5 \mathrm{~min}$, followed by 35 cycles of denaturation

114 at $95^{\circ} \mathrm{C}$ for $30 \mathrm{~s}$, annealing at $40 \mathrm{~s}$, and extension at $72^{\circ} \mathrm{C}$ for $40 \mathrm{~s}$, followed by a final

115 extension at $72^{\circ} \mathrm{C}$ for $5 \mathrm{~min}$. The PCR products were purified with polyethylene glycol

116 (PEG) and ethanol. The sequence reactions were run with the Big Dye kit (Applied

117 Biosystems), and the samples were sequenced in an ABI 3500 XL automatic sequencer

118 (Applied Biosystems). The access numbers on GenBank of the sequences produced in

119 the present study are available in the supplementary table S1.

121 Alignment of the sequences, evolutionary models, phylogenetic analyses, and

122 divergence times

123 The DNA sequences were aligned in ClustalW (Thompson et al., 1994) and

124 edited manually in BioEdit v. 7.2.5 (Hall, 1999). The outgroup was composed of

125 samples of the five remaining pitheciid genera, Callicebus, Plecturocebus, Pithecia,

126 Cacajao, and Chiropotes. PartitionFinder v.2 (Lanfear et al., 2016) was used to identify

127 the best data partitioning scheme and evolutionary models. We used the greedy

128 algorithm (Lanfear et al. 2012) and the Bayesian Information Criterion (BIC) and

129 protein coding regions were partitioned by position of the bases in the codons. Were

130 performed analysis for all concatenated markers, only nuclear regions, mitochondrial 
131 regions and each individual molecular marker. The data partitioning schemes and their respective evolutionary models can be viewed in the supplementary files (Table S2).

134 Bayesian Inference (BI) and coalescent approaches. The ML analysis was run in

135 RAxML v.8 (Stamatakis, 2014). The ML trees was found by 1000 searches followed by

1361000 bootstrap pseudoreplicates. The BI was run in MrBayes v.3.2.1 (Ronquist and

137 Huelsenbeck, 2003) with two independent Markov chain Monte Carlo (MCMC) runs,

138 one cold and three hot, with 500,000 generations, and trees and parameters sampled

139 every 5000 generations. The first $20 \%$ of the runs were discarded as burn-in. The

140 species tree with a multi-species coalescent model was estimated with ASTRAL III

141 (Zhang et al., 2018). ASTRAL uses non-rooted gene trees as the input file. We use the trees of the individual loci estimated in RaxML.

The percentage of genetic divergence between taxa was estimated with MEGA

144 v.6 (Tamura et al. 2013). We perform genetic distance analyzes for all concatenated

145 molecular markers, and for mitochondrial and nuclear data separately. We use K2P for

146 all analyzes of genetic distance.

147 Divergence times were estimated in BEAST v.1.8.3 (Drummond et al., 2012),

148 using two calibration points: (i) the Cacajao-Chiropotes separation, estimated at

$1496.7 \pm 2.3$ million years ago (Ma) (Kiesling et al. 2015); (ii) a pitheciine fossil, Nuciruptor

150 rubricae (Meldrum \& Kay, 1997) dated to 12.4-12.8 Ma, used in the node that groups

151 Pithecia, Chiropotes and Cacajao. Evolutionary models were assigned to each

152 molecular marker, following PartitionFinder. An uncorrelated relaxed clock was applied

153 to the branch lengths and a Yule model was applied as the prior for the tree. The

154 analyses were based on three independent runs, and the log parameters and trees were 
Carneiro 8

155 summarized in LogCombiner v.1.8.3 and TreeAnnotator v.1.8.3 (Drummond et al.,

156 2013), respectively. The convergence of the runs was evaluated in Tracer v.1.6

157 (Rambaut et al., 2014), and an Effective Sample Size (ESS) of over 200 was considered

158 to be satisfactory.

159 Results

160 The 16 concatenated markers (nuclear and mitochondrial) provided a database

161 of 9427 base pairs (bps), 2181 bps from the mitochondrial sequences, and 7246 bps

162 from the nuclear sequences. Overall, approximately $16 \%$ of the data are missing due to

163 problems encountered in the amplification of the markers in all the samples.

164 The ML and BI had the same topology, both with maximum support values

165 (bootstraps or posterior probabilities) for most of the nodes (Figure 2). This analysis

166 separates the titis into three main clades, as suggested by Byrne et al. (2016), with

167 Cheracebus as the sister taxon of the clade composed of Callicebus and Plecturocebus.

168 Two well-supported clades were also identified within the genus Cheracebus,

169 one which included $C$. lugens and C. torquatus, and the other formed by C. regulus, $C$.

170 purinus, and C. lucifer. In this latter clade, C. lucifer was recuperated as the sister

171 species of the clade formed by C. regulus and C. purinus. All allelic diversity within

172 species was reciprocally monophyletic, and all the relationships within the genus

173 Cheracebus were strongly supported. The Phylogenetic analysis under the multi-species

174 coalescent model (Figure 3) recovered the same topology of probabilistic methods (ML

175 and IB), also with most of the nodes strongly supported. We obtained incongruity in the

176 phylogenetic position of $C$. torquatus when analyzed the mitochondrial and nuclear data

177 separately (Figura S1). Only mitochondrial data groups C. torquatus within of $C$. 
178 lugens, with $60 \%$ of bootstrap, making paraphyletic $C$. lugens. In contrast, only nuclear markers position C. torquatus as sister to other species of the genus Cheracebus. All the concatenated molecular markers have genetic distances of approximately

$181 \quad 13 \%$ separating the three titi genera, Cheracebus, Plecturocebus, and Callicebus (Table

182 4), whereas the mean genetic distance between Cheracebus species was $2.45 \%$. The

183 distances ranged from $0.9 \%$ between $C$. regulus and $C$. purinus to $4 \%$ between $C$.

184 lugens and C. purinus. The C. lugens specimens from opposite margins of the Negro

185 River were separated by a genetic distance of $1.47 \%$, a value similar to that recorded

186 between the two species (C. lugens and C. torquatus) in this clade. We also analyze

187 genetic distances separately using only mitochondrial and nuclear data. Mitochondrial

188 data has an average genetic distance 5.17 times greater than nuclear data (Table S3 and 189 S4)

190 The estimates of divergence times indicated that the present-day pitheciids

191 began to diversify approximately 19.22 Ma, with a 95\% Highest Posterior Densities

192 (HPD) range of 15.95-22.49 Ma (Figure 4). It is interesting to note that the estimated

193 timing of the first diversification within the pitheciines (13.58 Ma; 95\% HPD: 11.83-

$19415.33 \mathrm{Ma})$ is virtually the same as that of the first diversification within the callicebines,

195 given that the three lineages of the current genera Cheracebus, Plecturocebus and

196 Callicebus were already separated by 13.15 (95\% HPD: 10.13-17.69 Ma). The current

197 Cheracebus species diversified only during the Pliocene, at around $3.92 \mathrm{Ma}$ (95\% HPD:

198 2.97-4.87 Ma). Cheracebus regulus and C. purinus are the species that diverged most 199 recently, of only $1.93 \mathrm{Ma}$ (95\% HPD: $1.38-2.48 \mathrm{Ma})$. 


\section{Discussion}

Until recently, the titi monkeys were classified in five species groups within the genus Callicebus, although Byrne et al. (2016) proposed a new arrangement, in which the taxon was divided into three genera, Cheracebus, Plecturocebus, and Callicebus. The results of the analyses presented here provide further, conclusive support for this arrangement. The genetic distances between these lineages are comparable with those found between the other pitheciid genera, and appear to be consistent with the timing of the separation of the three genera, in the mid Miocene ( 10 Ma). In fact, the morphological differences among the three callicebines are smaller than those among

210 the three pitheciines. Even so, the DNA sequences support the recognition of the six 211 pitheciid genera conclusively.

Despite the lack of C. medemi samples, all the Cheracebus species were

213 recuperated as monophyletic groups in the present analysis, which is consistent eith the

214 morphological data (Groves, 2005; Hershkovitz, 1988, 1990; Kobayashi \& Langguth,

215 1999; van Roosmalen et al., 2002). The data on the phylogenetic relationships among

216 the Cheracebus species point to an initial dichotomy between the C. lugens/C.

217 torquatus and C. lucifer/C. purinus/C. regulus clades, which are found exclusively on 218 opposite margins of the Amazon River. Cheracebus lugens and C. torquatus occur on 219 the northern margin of the Amazon (Solimões) River, while the other clade is found on 220 the southern margin. 
224 proposed a date of approximately $7 \mathrm{Ma}$. Whether or not the formation of the Amazon

225 River determined the separation of the two Cheracebus clades, it was almost certainly

226 in place by at least $3 \mathrm{Ma}$, and would have contributed to their genetic isolation.

227 Cheracebus lugens is the species with the largest geographic distribution of any

228 Cheracebus species, although the present analysis identified two clades with a genetic

229 distance of $1.4 \%$, a value greater than that found between some pairs of recognized

230 species, such as C. regulus and C. purinus, which were separated by a distance of $0.9 \%$.

231 Based on this parameter alone, the data suggest the existence of two valid species

232 within $C$. lugens, although this inference may be premature, given that many species,

233 even well-defined ones, may present intraspecific genetic divergences derived from

234 distinct mutation rates and/or patterns of genetic drift. Furthermore, this genetic

235 distance may be related to the ample geographic distance between the samples, and it is

236 possible that the analysis of a broader sample including additional localities may reveal

237 a more intermediate genetic distance. Further research will be needed to resolve this

238 question.

240 Conclusions

241 The present study is the first to test the monophyly of the genus Cheracebus

242 systematically, and define interspecific phylogenetic relationships based on DNA

243 sequences. The results of the study clearly support the monophyly of Cheracebus.

244 However, the phylogenetic position of C. medemi remains unclear. This species has a

245 restricted geographic distribution in the Caquetá and Putumayo departments of

246 Colombia. The phylogenetic reconstruction indicated that the initial diversification of

247 the extant species led to the formation of two reciprocal, monophyletic clades on 
248 opposite margins of the Amazon River at around 4 Ma. The origin of the clades may

249 thus be associated with the formation of the Amazon drainage system. As the

250 divergence of Cheracebus from the other callicebine genera occurred at approximately

$25113 \mathrm{Ma}$, this lineage either remained stable (with no speciation) for around $9 \mathrm{Ma}$ or the

252 forms derived from the speciation processes that occurred during this period are now

253 extinct, and may only exist in fossil form. The two clades of $C$. lugens identified in the

254 present study, based on their accentuated genetic distance, indicate the existence of a

255 new, as yet unidentified species of Cheracebus. However, confirmation of this

256 hypothesis will require further genetic and morphological samples from the geographic

257 range of $C$. lugens.

258

259 Ethics

260 All stages of the experiments and fieldwork were carried out in accordance with

261 Brazilian laws about primate research as well as the rules established by the American

262 Society of Primatologists in relation to the ethical treatment of primates. Research permits

263 were granted by Brazilian authorities (FUNAI and IBAMA/ICMBio), and by institutional

264 IACUC committees. The licenses to fieldwork and collection of tissue samples were

265 provided by IBAMA (License $N^{\circ} 005 / 2005$ - CGFAU/LIC) and ICMBio (40217-1 and $266 \quad 5135-1)$

267

268

269 Competing interests

$270 \quad$ We have no competing interests

271 
272

273

274

275

276

277

278

279

280

281

282

283

284

285

286

287

288

289

\section{Authors' contributions}

JC conceived of the study, participated in the data analyses and drafted the manuscript; IS designed the study, provided samples; TL carried out the molecular laboratory work and drafted the manuscript, JSSJ provided input on the manuscript, and revised the text; JB, IF, TH and JV provided samples and revised the manuscript; HS provided samples, and participated in the data analyses and the final revision of manuscript. All authors have approved the final version of the manuscript for publication.

\section{Acknowledgements}

We thank Luciana Watanabe, the laboratory technician at the Bragança campus of the Federal University of Pará for her support in processing the primate DNA samples, and Stephen Nash for the magnificent drawings provided for this study. Funding: this study was part of JC's doctoral thesis, which was supported by the Coordination for Higher Education Personnel Training (CAPES). It was also supported by funds provided by CAPES-PROAM 3296/2013 and CNPq (grants 306233/2009-6 to IS, and 473341/2010-7 and 305645/2009-9 to HS). Six field expeditions were funded in part by grants from CNPq/FAPEAM SISBIOTA Program (No. 563348/2010-0), CAPES/PROAMAZONIA/AUXPE (grant no. 3261/2013) to IPF. 
290

291

292

293

294 Byrne, H., Rylands, A. B., Carneiro, J. C., Alfaro, J. W. L., Bertuol, F., da Silva, M. N.

\section{References}

Batzer, M. A. (2005). Alu insertion loci and platyrrhine primate phylogeny. Molecular phylogenetics and evolution, 35(1), 117-126.

https://doi.org/10.1016/j.ympev.2004.10.023.

295 F., \& Boubli, J. P. (2016). Phylogenetic relationships of the New World titi monkeys

296 (Callicebus): first appraisal of taxonomy based on molecular evidence. Frontiers in

297 Zoology, 13(1), 10. https://doi.org/10.1186/s12983-016-0142-4.

298 Carneiro, J., Silva Junior, J. S., Sampaio, I., Pissinatti, A., Hrbek, T., Rezende Messias,

299 M., Rohe, F., Farias, I., Boubli, J. \& Schneider, H. (2016). Phylogeny of the titi

300 monkeys of the Callicebus moloch group (Pitheciidae, Primates). American journal of

301 primatology, 78(9), 904-913. https//doi.org/10.1002/ajp.22559.

302 Casado, F., Bonvicino, C. R., \& Seuanez, H. N. (2006). Phylogeographic analyses of

303 Callicebus lugens (Platyrrhini, Primates). Journal of Heredity, 98(1), 88-92.

304 https://doi.org/10.1093/jhered/es1054

305 Drummond, A. J., Suchard, M. A., Xie, D., \& Rambaut, A. (2012). Bayesian

306 phylogenetics with BEAUti and the BEAST 1.7. Molecular Biology and Evolution,

307 29(8), 1969-1973. https://doi.org/10.1093/molbev/mss075

308 Groves, C. P. (2005). Order Primates. Mammal species of the world: a taxonomic and 309 geographic reference, 1(3), 111-151. 
310 Hall, T. A. (1999). BioEdit: a user-friendly biological sequence alignment editor and

311 analysis program for Windows 95/98/NT. Nucleic Acids Symposium Series, 41, 95-98.

312 Hershkovitz, P. (1963). A systematic and zoogeographic account of the monkeys of the

313 genus Callicebus (Cebidae) of the Amazonas and Orinoco river basins. Mammalia,

314 27(1), 1-80. https://doi.org/10.1515/mamm.1963.27.1.1

315 Hershkovitz, P. (1988). Origin, speciation, and distribution of South American titi

316 monkeys, genus Callicebus (Family Cebidae, Platyrrhini). Proceedings of the Academy

317 of Natural Sciences of Philadelphia, 140(1), 240-272.

318 Hershkovitz, P. (1990). Titis, New World monkeys of the genus Callicebus (Cebidae,

319 Platyrrhini): a preliminary taxonomic review. Fieldiana, Zool. New Series, Field

320 Museum of Natural History, Chicago.

321 Hoorn, C., Wesselingh, F. P., Ter Steege, H., Bermudez, M. A., Mora, A., Sevink, J., \&

322 Antonelli, A. (2010). Amazonia through time: Andean uplift, climate change, landscape 323 evolution, and biodiversity. Science, 330(6006), 927-931.

324 https://doi:org/10.1126/science.1194585.

325 Kiesling, N. M. J., Soojin, V. Y., Xu, K., Sperone, F. G., \& Wildman, D. E. (2015). The 326 tempo and mode of New World monkey evolution and biogeography in the context of 327 phylogenomic analysis. Molecular Phylogenetics and Evolution, 82, 386-399.

328 https://doi.org/10.1016/j.ympev.2014.03.027.

329 Kobayashi, S. (1995). A phylogenetic study of titi monkeys, genus Callicebus, based on 330 cranial measurements: I. Phyletic groups of Callicebus. Primates, 36(1), 101-120. 
331 Kobayashi, S., \& Langguth, A. (1999). A new species of titi monkey, Callicebus

332 Thomas, from north-eastern Brazil (Primates, Cebidae). Revista Brasileira de Zoologia,

333 16(2), 531-551. http://dx.doi.org/10.1590/S0101-81751999000200018.

334 Lanfear, R., Calcott, B., Simon, Y.W.H., Guindon, S. (2016). PartitionFinder: combined

335 selection of partition schemes and substitution models for phylogenetics analyses.

336 Molecular biology and evolution, 29(6), 1695-1701.

337 https://doi.org/10.1093/molbev/mss020.

338 Lanfear, R., Frandsen, P. B., Wright, A. M., Senfeld, T., \& Calcott, B. (2016).

339 PartitionFinder 2: new methods for selecting partitioned models of evolution for

340 molecular and morphological phylogenetic analyses. Molecular biology and evolution,

$34134(3), 772-773$. https://doi.org/10.1093/molbev/msw260.

342 Meldrum, D. J., \& Kay, R. F. (1997). Nuciruptor rubricae, a new Pitheciin seed

343 predator from the Miocene of Colombia. American Journal of Physical Anthropology,

344 102(3), 407-427. https://doi.org/10.1002/(SICI)1096-8644(199703)102:3<407::AID-

345 AJPA8 $>3.0 . \mathrm{CO} ; 2-\mathrm{R}$.

346 Osterholz, M., Walter, L., \& Roos, C. (2009). Retropositional events consolidate the

347 branching order among New World monkey genera. Molecular Phylogenetics and

348 Evolution, 50(3), 507-513. https://doi.org/10.1016/j.ympev.2008.12.014.

349 Palumbi, S., Martin, A., \& Romano, S. (1991). 16s RNA primers. The simple fool's

350 guide to PCR, version, 2, 28. 
351 Perelman, P., Johnson, W. E., Roos, C., Seuánez, H. N., Horvath, J. E., Moreira, [...] \&

352 Pecon-Slaterry, J. (2011). A molecular phylogeny of living primates. PLoS Genet, 7(3), 353 e1001342. https://doi.org/10.1371/journal.pgen.1001342.

354 Rambaut, A., Suchard, M., Xie, W., \& Drummond, A. (2014). Tracer v. 1.6. Institute of 355 Evolutionary Biology, University of Edinburgh.

356 Ray, D. A., Xing, J., Hedges, D. J., Hall, M. A., Laborde, M. E., Anders, B. A., [...] \&

357 Cracraft, J. (2012). A palaeobiogeographic model for biotic diversification within

358 Amazonia over the past three million years. Proceedings of the Royal Society B:

359 Biological Sciences, 279(1729), 681-689. https://doi.org/10.1098/rspb.2011.1120.

360 Ronquist, F., \& Huelsenbeck, J. P. (2003). MrBayes 3: Bayesian phylogenetic inference

361 under mixed models. Bioinformatics, 19(12), 1572-1574.

362 https://doi.org/10.1093/bioinformatics/btg180.

363 Silva Júnior, J. S. (2013). Biogeography of the Amazonian primates. Conference at the

364 2nd Latin American Congress of Primatology and 15th Brazilian Congress of

365 Primatology.

366 Stamatakis, A. (2014). RAxML version 8: a tool for phylogenetic analysis and post-

367 analysis of large phylogenies. Bioinformatics, 30(9), 1312-1313.

368 https://doi.org/10.1093/bioinformatics/btu033

369 Tamura, K., Stecher, G., Peterson, D., Filipski, A., \& Kumar, S. (2013). MEGA6:

370 Molecular Evolutionary Genetics Analysis Version 6.0. Molecular Biology and

371 Evolution, 30(12), 2725-2729. https://doi:org/10.1093/molbev/mst197. 
372 Teeling, E. C., Scally, M., Kao, D. J., Romagnoli, M. L., Springer, M. S., \& Stanhope,

373 M. J. (2000). Molecular evidence regarding the origin of echolocation and flight in

374 bats. Nature, 403(6766), 188-192. https://doi.org/10.1038/35003188.

375 Thomas, O. (1903). XLIV.- Notes on South-American monkeys, bats, carnivores, and

376 rodents, with descriptions of new species. Annals and Magazine of Natural History,

377 12(70), 455-464.

378 Thompson, J. D., Higgins, D. G., \& Gibson, T. J. (1994). CLUSTAL W: improving the

379 sensitivity of progressive multiple sequence alignment through sequence weighting,

380 position-specific gap penalties and weight matrix choice. Nucleic Acids Research,

381 22(22), 4673-4680. https://doi:org/10.1093/nar/22.22.4673.

382 van Roosmalen, M. G. M., van Roosmalen, T., \& Mittermeier, R. A. (2002). A

383 taxonomic review of the titi monkeys, genus Callicebus Thomas, 1903, with the

384 description of two new species, Callicebus bernhardi and Callicebus stephennashi,

385 from Brazilian Amazonia. Neotropical Primates, 10(Suppl.), 1-52.

386 https://doi:org/10.1007/s10533-007-9087-1.

387 Ward, R. D., Zemlak, T. S., Innes, B. H., Last, P. R., \& Hebert, P. D. (2005). DNA

388 barcoding Australia's fish species. Philosophical Transactions of the Royal Society B:

389 Biological Sciences, 360(1462), 1847-1857.

390 Zang, C., Rabiee, M., Sayyari, E., \& Mirarab, S. (2018). ASTRAL-III: polynomial time

391 species tree reconstruction from partially resolved gene trees. BMC bioinformatics,

392 19(6), 153. https://doi.org/10.1186/s12859-018-2129-y. 


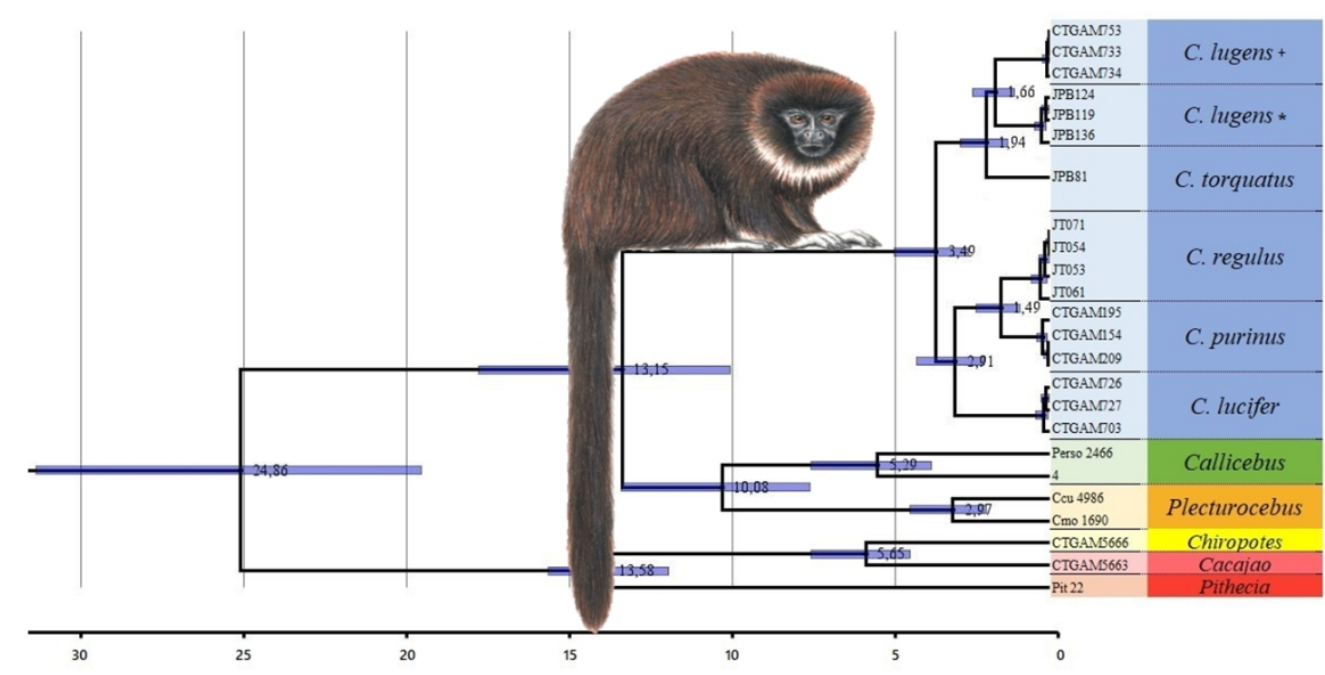

$338 \times 190 \mathrm{~mm}(96 \times 96 \mathrm{DPI})$

John Wiley \& Sons 
Highlights:

- $\quad$ Cheracebus is a genus of the subfamily Callicebinae;

- $\quad$ Cheracebus lineages originated approximately 13 ma ago;

- The phylogenetic relationships between the species of th genus Cheracebus are as follows: ((C. torquatus, C. lugens), (C. lucifer, (C. purinus, C. regulus $)))$. 
Figure 1. Distribution map of Cheracebus species (Hershkovitz, 1990; van Roosmalen et al., 2002). Dotted region represents a possible zone of sympathy between $C$. lugens and $C$. torquatus species. The symbols represent the locations where the samples were collected.

\section{$338 \times 190 \mathrm{~mm}(96 \times 96 \mathrm{DPI})$}


Figure 2. Phylogenetic relationships between taxa of the Pitheciidae family. Numbers near nodes refer to bootstrap (left) and posterior probability (right) values.

\section{$338 \times 190 \mathrm{~mm}(96 \times 96$ DPI $)$}


aplecterporicedous moloch 1516

1

Plecturocebus cupreus 210

1

1

Callicebus personatus 2466

Callicebus nigrifrons

Cheracebus torquatus JPB81

Cheracebus lugens JPB124

Cheracebus lugens CTGAM119

0.9

0.87 Cheracebus lugens CTGAM136

Cheracebus lugens CTGAM734

0.81

Cheracebus lugens CTGAM733

0.37

Cheracebus lugens CTGAM753

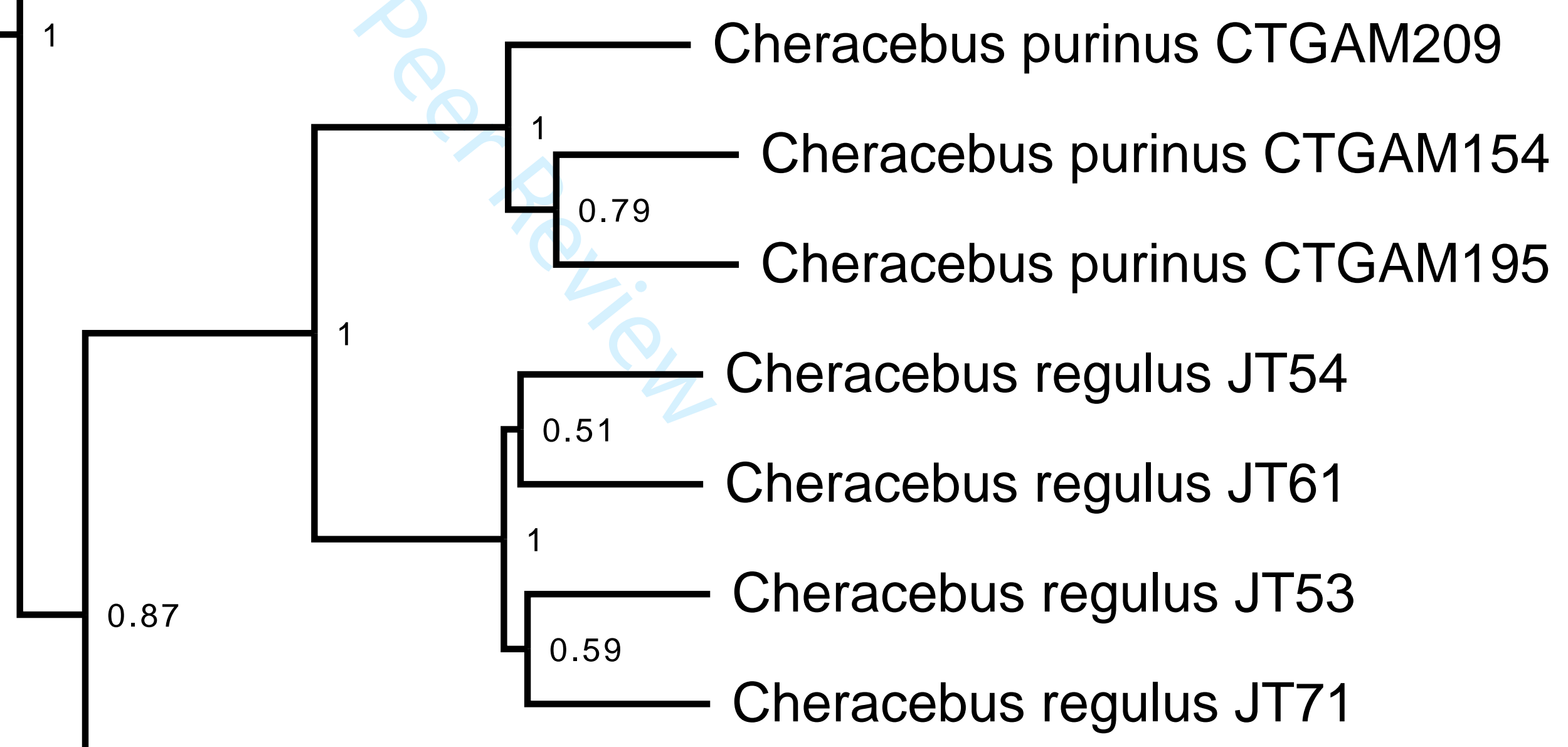

0.95

Cheracebus lucifer CTGAM703

Cheracebus lucifer CTGAM727

0.33 Cheracebus lucifer CTGAM726

Pithecia

Chiropotes

1 Cacajao 
Figure 4. Estimated divergence time between Pitheciidae taxa. Each genus has a color: blue to Cheracebus, green to Callicebus, orange to Plecturocebus, yellow to Chiropotes; pink to Cacajao and red to Pithecia. (*) highlights clade of $\mathrm{C}$. lugens on the left bank of the river Negro, while (+) indicates the samples collected on the right bank of this river. Numbers next node represent the average time estimated by cladogenesis

$$
338 \times 190 \mathrm{~mm}(96 \times 96 \mathrm{DPI})
$$


Table 1. Hypotheses for classification of titi monkeys.

\begin{tabular}{|c|c|c|c|c|}
\hline $\begin{array}{l}\text { Callicebus donacophilus } \\
\text { group }\end{array}$ & $\begin{array}{l}\text { Callicebus donacophilus } \\
\text { group }\end{array}$ & $\begin{array}{l}\text { Callicebus donacophilus } \\
\text { group }\end{array}$ & $\begin{array}{l}\text { Subgenus Callicebus } \\
\text { Callicebus group }\end{array}$ & Genus Plecturocebus \\
\hline C. d. donacophilus & C. modestus & C. modestus & C. donacophilus & P. modestus \\
\hline C. d. pallescens & C. d. donacophilus & C. donacophilus & C. pallescens & P. donacophilus \\
\hline C. olallae & C. olallae & C. oenanthe & C. olallae & P. oenanthe \\
\hline & & C. olallae & & P. olallae \\
\hline $\begin{array}{l}\text { Callicebus moloch group } \\
\text { C. moloch }\end{array}$ & $\begin{array}{l}\text { Callicebus moloch group } \\
\text { C. moloch }\end{array}$ & $\begin{array}{l}\text { Callicebus moloch group } \\
\text { C. moloch }\end{array}$ & $\begin{array}{l}\text { Callicebus moloch group } \\
\text { C. moloch }\end{array}$ & $\begin{array}{l}\text { P. moloch } \\
\text { P. cinerascens } \\
\text { P. brunneus }\end{array}$ \\
\hline C. cinerascens & C. cinerascens & C. cinerascens & C. cinerascens & P. hoffmannsi \\
\hline C. caligatus & & C. bernhardi & C. bernhardi & P. caligatus \\
\hline C. brunneus & & & & P. discolor \\
\hline C. hoffmannsi hoffmannsi & Callicebus cupreus group & Callicebus cupreus group & Callicebus cupreus group & P. ornatos \\
\hline C. h. baptista & C. с. cupreus & C. cupreus & C. cupreus & P. dubius \\
\hline C. dubius & C. c. discolor & C. caligatus & C. caligatus & P. stephennashi \\
\hline C. personatus personatus & C. ornatos & C. discolor & C. discolor & P. aureipalatii \\
\hline C.p. melanochir & & C. ornatos & C. ornatos & P. toppini \\
\hline
\end{tabular}



C. p. nigrifrons
C. dubius
C. dubius
P. urubambensis
C. p. barbarabrownae
C. stephennashi
C. stephennashi
P. miltoni
Callicebus modestus group
Callicebus modestus group
C. modestus
P. caquetensis
C. modestus

Callicebus personatus group Callicebus personatus group Callicebus personatus group Genus Callicebus
C. personatus
C. melanochir
C. nigrifrons
C. barbarabrownae
C. coimbrai
C. melanochir
C. nigrifrons
C. barbarabrownae
C. coimbrai

C. personatus
C. personatus
C. melanochir
C. nigrifrons
C. barbarabrownae
C. coimbrai
C. personatus
C. melanochir
C. nigrifrons
C. barbarabrownae
C. coimbrai

\section{Callicebus torquatus group}

C. torquatus

C. lugens

C. lucifer

C. purinus

C. regulus

C. medemi

\section{Callicebus torquatus group}

C. torquatus

C. lugens

C. lucifer

C. purinus

C. regulus

C. medemi

\section{Genus Cheracebus}

C. torquatus

C. lugens

C. lucifer

C. purinus

C. regulus

C. medemi 
Table 2. Samples used in the present study and their respective codes, origins and locations.

\begin{tabular}{|c|c|c|c|}
\hline Specie & Code & Origin & Locality \\
\hline Cheracebus torquatus & JPB81 & INPA & Mandiquie, right bank of river Negro, Amazonas, Brazil \\
\hline Cheracebus lugens & JPB119 & INPA & Marari, left bank of river Negro, Amazonas, Brazil \\
\hline Cheracebus lugens & JPB124 & INPA & Igarapé Anta, left bank of river Negro, Amazonas, Brazil \\
\hline Cheracebus lugens & JPB136 & INPA & Igarapé Cuieiras, left bank of river Negro, Amazonas, Brazil \\
\hline Cheracebus lugens & CTGAM733 & UFAM & Left bank of river Japurá, Amazonas, Brazil \\
\hline Cheracebus lugens & CTGAM734 & UFAM & Left bank of river Rio Japurá, Amazonas, Brazil \\
\hline Cheracebus lugens & CTGAM753 & UFAM & Left bank of river Japurá, Amazonas, Brazil \\
\hline Cheracebus purinus & CTGAM154 & UFAM & Rebio Abufari, left bank of river Purus, Amazonas, Brazil \\
\hline Cheracebus purinus & CTGAM195 & UFAM & Rebio Abufari, left bank of river Purus, Amazonas, Brazil \\
\hline Cheracebus purinus & CTGAM209 & UFAM & Rebio Abufari, left bank of river Purus, Amazonas, Brazil \\
\hline Cheracebus lucifer & CTGAM703 & UFAM & Right bank of river Rio Japurá, Amazonas, Brazil \\
\hline Cheracebus lucifer & CTGAM726 & UFAM & Right bank of river Rio Japurá, Amazonas, Brazil \\
\hline Cheracebus lucifer & CTGAM727 & UFAM & Right bank of river Rio Japurá, Amazonas, Brazil \\
\hline Cheracebus regulus & JT053 & UFPA & Right bank of river Jutaí, Amazonas, Brazil \\
\hline Cheracebus regulus & JT054 & UFPA & Right bank of river Jutaí, Amazonas, Brazil \\
\hline Cheracebus regulus & JT061 & UFPA & Right bank of river Jutaí, Amazonas, Brazil \\
\hline Cheracebus regulus & JT071 & UFPA & Right bank of river Jutaí, Amazonas, Brazil \\
\hline Plecturocebus moloch & Cmo 1690 & UFPA & Left bank of river Tocantins, Amazonas, Brazil \\
\hline Plecturocebus brunneus & Cbr 2220 & UFPA & Right bank of river Jamari, Rondonia, Brazil \\
\hline Plecturocebus cupreus & Ccu 4986 & UFPA & Left bank of river Madeira, Amazonas, Brazil \\
\hline Callicebus melanochir & melan 2329 & CNRJ & Eunápolis, Bahia, Brazil \\
\hline Callicebus personatus & perso 2466 & CNRJ & Aracruz, Espirito Santo, Brazil \\
\hline Callicebus nigrifrons & 04 & PUC & Minas Gerais, Brazil \\
\hline Chiropotes albinasus & CTGAM5663 & UFPA & Right bank of river Tapajos \\
\hline
\end{tabular}




\begin{tabular}{llll} 
Cacajao calvus & CTGAM5666 & UFPA & No information \\
Pithecia pithecia & Pit 22 & UFPA & Left bank of river Jari, Amapá, Brasil \\
\hline
\end{tabular}


Table 3. Molecular markers used in this study, with their annealing temperatures and references.

\begin{tabular}{|c|c|c|c|c|}
\hline $\begin{array}{c}\text { Molecular } \\
\text { markers }\end{array}$ & Primer forward & Primer reverse & $\begin{array}{c}\text { Annealing } \\
\text { Temperature }\end{array}$ & Reference \\
\hline \multicolumn{5}{|c|}{ Mitochondrial } \\
\hline $\mathrm{COI}$ & 5' TCCATTACCAGGCCAGCTAG 3' & 5' GAACTTGCTGGCTTTCATATC 3' & $45^{\circ} \mathrm{C}$ & Ward et al. (2005) \\
\hline CYT b & 5' GCACCTACCCACGAAAAGAA 3' & 5' ACATTGCCTCTGCAAATTGA 3' & $60{ }^{\circ} \mathrm{C}$ & Carneiro et al. (2016) \\
\hline \multicolumn{5}{|c|}{ Nuclear } \\
\hline Pith_Alu1D_27 & 5' AACCACATTTTGACTGTATGCTG 3' & 5' CCCTTCAATGACTCCCTTCA 3' & $57^{\circ} \mathrm{C}$ & Ray et al. (2005) \\
\hline Pith_Alu1D_30 & 5' CATGGGACATGCACTTTTTG 3' & 5' AACAYCTTYCATCAACCTYTGAA 3' & $61{ }^{\circ} \mathrm{C}$ & Ray et al. (2005) \\
\hline Titi_1DF2_39 & 5'AACAGAGTTGGCCGTTCATCT 3' & 5' GTCCTGTTCAAGTCAGCTACGTTG 3' & $54{ }^{\circ} \mathrm{C}$ & Ray et al. (2005) \\
\hline Pith_Alu1D_84 & 5' CTGCTACGTCAGACGTCGTAC 3' & 5' CTGCTAGCACAAGCTAGTCGA 3' & $62{ }^{\circ} \mathrm{C}$ & Ray et al. (2005) \\
\hline Pitheciidae2 & 5' CAGCCAAAGGAGTGCTTCAC 3' & 5' CTAAATGGTGYCCCATAAGG 3' & $58^{\circ} \mathrm{C}$ & Osterholz et al. (2009) \\
\hline ZFX & 5' TGGAATGAAATCCCTCAAATA 3' & 5' ATGTCCATCAGGGCCAATAAT 3' & $52{ }^{\circ} \mathrm{C}$ & Perelman et al. (2011) \\
\hline RAG1 & 5' GCTTTGATGGACATGGAAGAAGACAT 3' & 5' GAGCCATCCСТCTCAATAATTTCAGG 3' & $47^{\circ} \mathrm{C}$ & Teeling et al. (2000) \\
\hline
\end{tabular}


Table 4. Genetic distance between species of the genus Cheracebus and taxa of the family Pitheciidae.

\begin{tabular}{|c|c|c|c|c|c|c|c|c|c|c|c|}
\hline & & 1 & 2 & 3 & 4 & 5 & 6 & 7 & 8 & 9 & 10 \\
\hline 1 & Cheracebus lugens * & & & & & & & & & & \\
\hline 2 & Cheracebus lugens + & 1.47 & & & & & & & & & \\
\hline 3 & Cheracebus torquatus & 1.67 & 1.73 & & & & & & & & \\
\hline 4 & Cheracebus regulus & 2.80 & 3.27 & 2.67 & & & & & & & \\
\hline 5 & Cheracebus purinus & 3.39 & 4.00 & 3.38 & 0.97 & & & & & & \\
\hline 6 & Cheracebus lucifer & 3.59 & 3.79 & 3.18 & 2.01 & 2.92 & & & & & \\
\hline 7 & Plecturocebus & 13.7 & 13.3 & 12.6 & 13.1 & 13.9 & 13.2 & & & & \\
\hline 8 & Callicebus & 12.6 & 12.4 & 12.3 & 12.7 & 13.3 & 12.9 & 13.0 & & & \\
\hline 9 & Chiropotes & 22.4 & 22.3 & 21.6 & 22.1 & 22.6 & 22.7 & 21.8 & 22.4 & & \\
\hline 10 & Cacajao & 21.1 & 20.9 & 20.3 & 20.8 & 21.3 & 21.4 & 22.0 & 21.1 & 12.7 & \\
\hline 11 & Pithecia & 27.6 & 27.4 & 25.3 & 25.2 & 24.9 & 26.7 & 25.7 & 25.9 & 17.9 & 16.2 \\
\hline
\end{tabular}



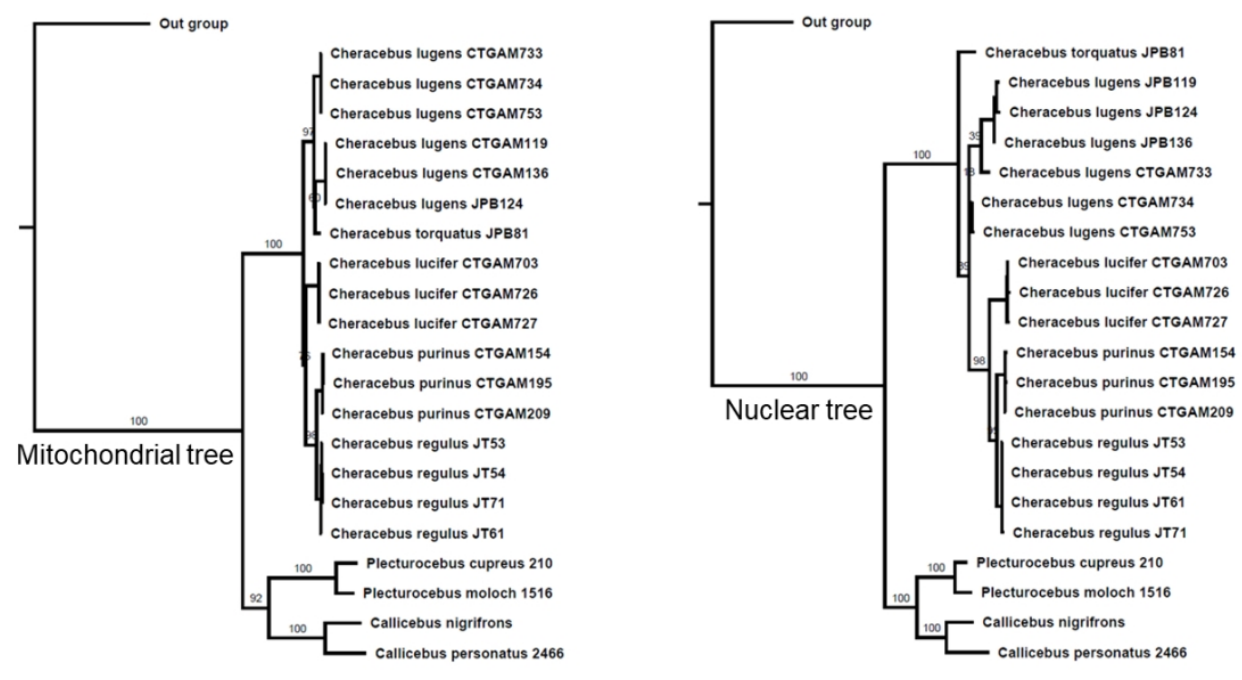

$338 \times 190 \mathrm{~mm}(96 \times 96$ DPI)

John Wiley \& Sons 
Table S1. Markers and their access numbers in GenBank.

\begin{tabular}{llr}
\hline Marker & \multicolumn{2}{c}{ Access number range } \\
\hline ZFX & MT011236 & MT011248 \\
SIM 1 & MT011223 & MT011235 \\
Alu_Pitheciidae4 & MT011205 & MT011222 \\
Alu_Pitheciidae3 & MT011186 & MT011204 \\
Alu_Pitheciidae2 & MT011167 & MT011185 \\
Pith_Alu1D_84 & MT011148 & MT011166 \\
Titi_1DF2_39 & MT011128 & MT011147 \\
Pith_Alu1D_30 & MT011113 & MT011127 \\
Pith_Alu1D_27 & MT011092 & MT011112 \\
Cytochromeb & MN998472 & MN998495 \\
rRNA 16S & MT002404 & MT002424 \\
Cytochrome oxidase I & MN998547 & MN998570 \\
Pith_Alu1D_26 & MN998449 & MN998471 \\
Pith_Alu1D_24 & MN998428 & MN998448 \\
RAG 1 & MN998418 & MN998427 \\
\hline
\end{tabular}


Table S2. Data partitioning scheme, markers and respective evolutionary models.

\begin{tabular}{|c|c|c|c|}
\hline $\begin{array}{l}\text { Number } \\
\text { of } \\
\text { Partitions }\end{array}$ & Partition names & $\begin{array}{c}\text { Evolutionary } \\
\text { Models }\end{array}$ & $\begin{array}{c}\text { Numbers } \\
\text { of sites }\end{array}$ \\
\hline \multicolumn{4}{|c|}{ All molecular markers } \\
\hline $\mathrm{I}$ & $\begin{array}{l}\text { Cyt B_pos1, 16S, SIM1, RAG1_pos2, Cyt } \\
\text { B_pos2, COI_pos2, Alu84, RAG1_pos3, } \\
\text { Alu27, PITH3, RAG1_pos1, DENND5A, } \\
\text { COI_pos1, Alu39, PITH2, Alu30, Alu26, } \\
\text { ZFX, PITH4, Alu24 }\end{array}$ & $\mathrm{TRN}+\mathrm{G}$ & 9191 \\
\hline II & COI_pos3, CYTB_pos3 & $\mathrm{TRN}+\mathrm{G}$ & 564 \\
\hline \multicolumn{4}{|c|}{ Only nuclear markers } \\
\hline $\mathrm{I}$ & $\begin{array}{l}\text { Alu24, Alu26, Alu27, Alu30, Alu39, Alu84, } \\
\text { DENND5A, PITH2, PITH3, PITH4, } \\
\text { RAG1_pos1, RAG1_pos2, RAG1_pos3, } \\
\text { SIM1, ZFX }\end{array}$ & $\mathrm{HKY}+\mathrm{G}$ & 7574 \\
\hline \multicolumn{4}{|c|}{ Only mitochondrials markers } \\
\hline I & 16S, COI pos1, Cyt B pos1 & $\mathrm{GTR}+\mathrm{G}$ & 1052 \\
\hline II & COI pos2, Cyt B pos2 & $\mathrm{HKY}+\mathrm{I}$ & 565 \\
\hline III & COI_pos3, Cyt B_pos3 & $\mathrm{TRN}+\mathrm{G}$ & 564 \\
\hline \multicolumn{4}{|c|}{ Individual molecular markers } \\
\hline & $16 \mathrm{~S}$ & $\mathrm{GTR}+\mathrm{G}$ & 486 \\
\hline & COI & $\mathrm{GTR}+\mathrm{G}$ & 623 \\
\hline & Cyt B & $\mathrm{GTR}+\mathrm{I}$ & 1072 \\
\hline & Alu24 & GTR & 330 \\
\hline & Alu26 & GTR & 390 \\
\hline & Alu27 & $\mathrm{GTR}+\mathrm{G}$ & 636 \\
\hline & Alu30 & GTR & 693 \\
\hline & Alu39 & GTR & 431 \\
\hline & Alu84 & GTR & 480 \\
\hline & DENND5A & GTR & 637 \\
\hline & PITH2 & GTR & 179 \\
\hline & PITH3 & GTR & 537 \\
\hline & PITH4 & GTR & 491 \\
\hline & RAG1 & $\mathrm{GTR}+\mathrm{I}$ & 1030 \\
\hline & SIM1 & GTR & 603 \\
\hline & ZFX & GTR & 809 \\
\hline
\end{tabular}


Table S3. Genetic distance of nuclear data between species of the genus Cheracebus and taxa of the family Pitheciidae.

\begin{tabular}{|c|c|c|c|c|c|c|c|c|c|c|c|}
\hline & & 1 & 2 & 3 & 4 & 5 & 6 & 7 & 8 & 9 & 10 \\
\hline 1 & Cheracebus lugens * & & & & & & & & & & \\
\hline 2 & Cheracebus lugens + & 0.26 & & & & & & & & & \\
\hline 3 & Cheracebus torquatus & 0.37 & 0.30 & & & & & & & & \\
\hline 4 & Cheracebus regulus & 1.22 & 0.40 & 0.45 & & & & & & & \\
\hline 5 & Cheracebus purinus & 0.84 & 0.65 & 0.48 & 0.27 & & & & & & \\
\hline 6 & Cheracebus lucifer & 1.13 & 0.27 & 0.47 & 0.38 & 0.55 & & & & & \\
\hline 7 & Plecturocebus & 2.71 & 3.24 & 1.47 & 3.58 & 2.60 & 3.56 & & & & \\
\hline 8 & Callicebus & 2.95 & 3.47 & 1.59 & 3.76 & 2.75 & 3.84 & 1.64 & & & \\
\hline 9 & Chiropotes & 4.67 & 6.63 & 4.05 & 6.47 & 4.33 & 6.47 & 4.40 & 4.95 & & \\
\hline 10 & Cacajao & 4.07 & 6.92 & 4.86 & 6.62 & 3.89 & 6.52 & 3.90 & 4.16 & 1.79 & \\
\hline 11 & Pithecia & 4.22 & 6.18 & 4.48 & 6.44 & 4.19 & 6.31 & 4.13 & 4.88 & 2.25 & 1.75 \\
\hline
\end{tabular}

$*$ and + mean left and right bank of the river Negro, respectively. 
Table S4. Genetic distance of mitochondrial data between species of the genus Cheracebus and taxa of the family Pitheciidae

\begin{tabular}{|c|c|c|c|c|c|c|c|c|c|c|c|}
\hline & & 1 & 2 & 3 & 4 & 5 & 6 & 7 & 8 & 9 & 10 \\
\hline 1 & Cheracebus lugens * & & & & & & & & & & \\
\hline 2 & Cheracebus lugens + & 1.89 & & & & & & & & & \\
\hline 3 & Cheracebus torquatus & 1.91 & 1.56 & & & & & & & & \\
\hline 4 & Cheracebus regulus & 3.54 & 3.32 & 3.50 & & & & & & & \\
\hline 5 & Cheracebus purinus & 3.90 & 3.63 & 3.56 & 1.16 & & & & & & \\
\hline 6 & Cheracebus lucifer & 4.25 & 3.42 & 3.36 & 3.06 & 3.12 & & & & & \\
\hline 7 & Plecturocebus & 12.40 & 12.39 & 13.10 & 11.80 & 12.21 & 3.41 & & & & \\
\hline 8 & Callicebus & 12.22 & 12.57 & 13.22 & 11.89 & 12.44 & 3.26 & 2.13 & & & \\
\hline 9 & Chiropotes & 17.99 & 18.54 & 20.14 & 17.94 & 18.68 & 9.83 & 18.59 & 18.74 & & \\
\hline 10 & Cacajao & 17.1 & 17.26 & 18.54 & 16.62 & 17.40 & 8.36 & 18.38 & 8.03 & 0.26 & \\
\hline 11 & Pithecia & 18.04 & 18.68 & 20.13 & 18.36 & 18.42 & 0.14 & 19.25 & 8.66 & 3.27 & 12.95 \\
\hline
\end{tabular}


Dear Dr. Carneiro,

I thank you for submitting your manuscript AJP-19-0267 entitled "Phylogenetic relationships in the genus $<i>$ Cheracebus $</ i>$ (Callicebinae, Pitheciidae)" for review and publication in the American Journal of Primatology. In light of my reading of your paper, as well as the evaluation of your Review Editor and the comments of the external reviewers, I am pleased to inform you that your paper is accepted pending minor revisions.

In addition to addressing the comments below, please include information regarding the ethical approvals for collection of the subject specimens. Specifically, please confirm both that the protocols were approved by the respective institutions, and that the research complied with the American Society of Primatologists Ethical Principles for the Treatment of Non-Human Primates.

$\mathrm{R}=\mathrm{We}$ incorporated in the manuscript the license number of the collection and that the research followed the ethical principles of American Society of Primatologists.

When submitting your revised manuscript, please provide an itemized response to reviewer(s) comments in the space labeled "Response to Decision Letter." Please note that if you copy and paste your response from a separate document, bold, italicized, and colored text from the original document will appear as black, upright/roman text.

Please make these revisions within two months or less from the date of this letter.

You can upload your revised manuscript and submit it through your Author Center. Log into https://mc.manuscriptcentral.com/ajp and enter your Author Center, where you will find your manuscript title listed under "Manuscripts with Decisions". 
IMPORTANT: We have your original files. When submitting (uploading) your revised manuscript, please delete the file(s) that you wish to replace and then upload the revised file(s).

Your article cannot be published until the corresponding author has signed the appropriate license agreement. Once the manuscript is accepted, the corresponding author will receive an email from Wiley's Author Services system which will ask them to log in and will present them with the appropriate license for completion.

We thank you for submitting your work to the American Journal of Primatology, and look forward to receiving your revised manuscript.

Sincerely,

Dr. Karen Bales

Editor-in-Chief, American Journal of Primatology ajpeditorialoffice@wiley.com

\section{EDITOR COMMENTS TO AUTHORS:}

Review Editor: Vigilant, Linda

Comments to the Author:

The authors present a focused study on the phylogenetic relationships of the titi monkeys that should be of interest to readers of AJP with a particular interest in primate phylogenies. I find it well-written, but concur with the reviewers that further experimental/analytical detail is needed and also that it is not acceptable to concatenate mitochondrial and nuclear sequences for analyses. Please see the review for detailed suggestions and I look forward to seeing a revised version of the manuscript soon. 


\section{REVIEWER COMMENTS TO AUTHORS:}

Reviewing: 1

Comments to the Author

The authors investigate phylogenetic relationships among 5 of the 6 species of Cheracebus. The authors can show that Cheracebus is indeed monophyletic and the branching pattern among the species is well resolved. The manuscript is well written, but some rewording is required. Methods and Results are well presented, but I am a little bit concerned about the fact that all analyses are done with a concatenated dataset; thus I recommed to redo some of the analyses.

\section{$\mathrm{R}=$ We performed analyzes of mitochondrial and nuclear data separately.} Additionally, we carried out a coalescent analysis following the suggestion of the reviewer 2.

Major points:

1. you use a concatenated dataset for all analyses. At least mitochondrial and nuclear data should be analysed separately; this concerns the phylogenetic trees, the dating as well as the genetic distance calculation. Particulary for the distance calculation, one would expect much larger differences in mtDNA compared to nuclear DNA. Trees based on the combined dataset can be presented as main figures and the individual trees in the supplement.

$\mathrm{R}=$ We performed analyzes of mitochondrial and nuclear data separately, the trees were included in the supplementary files. We also perform genetic distance analysis with mitochondrial and nuclear data separately.

2. please provide more information about the calibration points for dating: what settings were used in BEAST? Are the 2 points based on fossils, previous molecular dating, etc.? please give here more information. Probably also good to include addtional NWM genera and use more fossil-based calibrations 
$\mathrm{R}=$ We used $\mathrm{a}$ fossil and a calibration based on previous study. We rewrote this part of the text and include the appropriate reference to clarify.

3. I can not find any information about the applied substitution models for the overall dataset or individual loci

$\mathrm{R}=$ We made a table that shows all the evolutionary models used in this study.

Minor points:

1. Please check the numbers of your affiliations; they are not in order

2. 132 and 197: based on DNA sequencing of 16

3. 144: 13 million years ago

4. 181: which placed purinus in the

5. 191: Roosmalen et al. (2002)

6. 1113: Total genomic DNA

7. 1119: 30ng of genomic DNA

8. I122, I125 and Table3: annealing instead of hybridizing/hybridization

9. 1127: ethanol instead of alcohol; ... were run with the Big Dye

10. 1138: The ML trees

11. I140-2: with two independent Markov chain Monte Carlo (MCMC) runs, with 500,000 generations, and trees and parameters sampled every 5000 generations.

12. I144: estimated with MEGA (xxx) (Tamura et al. 2013).; add also what version was used

13. I147: abbreviation $\mathrm{Ma}$ is not explained before

14. 1151: LogCombiner v.1.8.3 and TreeAnnotator

15. I163: the clade composed of

16. I191: remove bracket after Callicebus

17. 1200: which is consistent eith the morphological data

18. Figures 1 and 2: both can be lumped into one

19. Table1: check arrangements in the Hershkovitz (1990) column

20. Table2: Genebank accession number sare missing; could be added to Table 2 or somewhere else 


\begin{abstract}
21. Table3: Mitochondrial instead of Mitochondrials; reference are not in reference list; emty space in reverse primer for RAG1; annealing NOT hybridization
\end{abstract}

$\mathrm{R}=$ Thanks for the corrections, all minor points were corrected.

Reviewing: 2

Comments to the Author

This work is a straightforward analysis of the phylogeny of a new genus of titi monkeys. The authors set out to test the monophyly of the newly proposed Cheracebus genus of neotropical primates. Using a larger sampling of loci, they confirmed earlier taxonomic proposals. Overall, their results are convincing, and the authors avoided going into speculations regarding the biogeography and causes of Cheracebus diversification. Because the subject of the manuscript is rather restricted, it will be of interest mainly to primatologists working on neotropical primate systematics. However, I think this is not a drawback. The only effective shortcoming is the absence of Cheracebus medemi sequences, which prevented the authors to make a de facto evaluation of the monophyly of the genus.

The authors should correct/clarify the following points:

- The authors should justify the concatenation of all loci into a single supergene instead of analyzing them independently. Although it is expected that mitochondrial genes will share the same evolutionary history, nuclear loci may have different histories if they are located either in different chromosomes or distantly enough in the same chromosome (a measure that will depend on the recombination rate). To make their work richer - and to further corroborate their findings - I suggest the authors to run a coalescent-based phylogenetic inference. You can try fast methods such as ASTRAL. There is no need to run a full coalescent inference in BEST, *BEAST or BPP (this will take many days and parameters will likely fail to converge). It might be the case that the coalescentbased phylogeny will be topologically identical to ML/BI. This is fine, because at 
least the methodological section will be improved: it is reasonable to employ such methods particularly when dealing with shallow divergences.

$\mathrm{R}=$ We performed analyzes of mitochondrial and nuclear data separately. Additionally, we carried out a coalescent analysis ASTRAL III.

- Figure 2 should be corrected (text in Portuguese in figure).

$\mathrm{R}=$ corriged. A new map was made

- The Methods section needs to be expanded. Please provide detailed information on the model of nucleotide substitution used in ML, BI and BEAST analyses.

$\mathrm{R}=$ We made a table that shows all the evolutionary models used in this study.

- Which node was calibrated by "the pitheciine fossil, Nuciruptor rubricae (Meldrum \& Kay, 1997), dated to 14812.4-12.8 Ma." Was it the root node? $\mathrm{R}=$ We used a fossil and a calibration based on previous study. We rewrote this part of the text and include the appropriate reference to clarify.

- "The 16 nuclear and mitochondrial markers provided a database of 9755 base pairs (bps), 2300 bps from the mitochondrial sequences, and 7455 bps from the nuclear sequence". An alignment of 9755 base pairs (bps)?

$\mathrm{R}=$ Yes, it is the alignment of the concatenated loci. We corrected that part of the text, the complete alignment actually has 9427 base pairs.

- "All the species were identified as monophyletic". I suggest using "All allelic diversity within species was reciprocally monophyletic".

$\mathrm{R}=$ We made the suggested change

- "is virtually the same as that of the first diversification within the callicebines" -$>$ close to the first?

$\mathrm{R}=$ there was a mistake. We wanted to refer to another node. The Split of Pithecia from the other pithecineos (Cacajao and Chiropotes). 
- "are the species with the shortest divergence time" --> earliest divergence time?

$\mathrm{R}=$ We were referring to the most recent speculations within the genus

Cheracebus. We rewrote to clarify

- Please clarify what you mean by "patterns of genetic drift".

$\mathrm{R}=$ We referred to random genetic drift events in different species. But we decided to remove that part of the text 